\title{
Medium-Chain Specific Acyl-CoA Dehydrogenase, Mitochondrial
}

National Cancer Institute

\section{Source}

National Cancer Institute. Medium-Chain Specific Acyl-CoA Dehydrogenase,

Mitochondrial. NCI Thesaurus. Code C82877.

Medium-chain specific acyl-CoA dehydrogenase, mitochondrial (421 aa, $\sim 47 \mathrm{kDa}$ ) is encoded by the human ACADM gene. This gene is involved in lipid oxidation. 